Review Article

\section{Bioactive components of tea}

\author{
Gargi Sen ${ }^{1 *}$, Nilanjan Sarkar², Moutusi Nath ${ }^{1}$ and Subhasis Maity² \\ 1Department of Optometry \& Vision Science, NSHM College of Management \& Technology, Kolkata, \\ India \\ ${ }^{2}$ Department of Pharmacy, NSHM Knowledge Campus, Kolkata - Group of Institutions, Kolkata, India
}

\section{Abstract}

Tea (Black tea and Green tea) are one of the most widely consumed beverages in the world. However, with the increasing interest in the health properties of tea and a significant rise in scientific investigation, this review covers some of the recent findings on the health benefits of both green and black tea. The mechanisms of action of various black and green tea components have been presented. Green tea contains a unique set of catechins that responsible for its biological activity potentially relevant to the prevention of diseases. Although there has been much focus on the biological property of the major tea catechins, black tea offers major health benefits either due to the presence of the catechins in epimerized form or some other active components of both varieties of tea. Characteristics unrelated to the antioxidant properties of green and black tea might also be responsible for their therapeutic potential in preventing diseases. Synergistic effect of the tea constituents is increasingly recognized as being potentially important to the medicinal benefits of black and green tea. The studies indicate that tea has the potential of being a part of diet for healthy living.

\section{Introduction}

Tea and infusion of the leaves of the Camellia sinensis, is a widely consumed aromatic beverage. Consumers vary in their preferences on the type of tea they consume, which in turn is dependent on the degree of fermentation, taste and color [1]. Tea is considered as a rejuvenator and often acts as therapeutic adjuvant for several aliments for people from all walks of life [2]. Various types of tea are popular in different regions of the world. Black tea (Bt) is consumed as beverage principally in India, Pakistan, Sri Lanka, Russia, Europe, North America, North Africa etc. and most of the processing of Bt involves intense crushing and fermentation process [3]. Green tea (Gt) is a lightly processed tea that is not fermented at all [4] and is widely consumed in China and Japan. Tea has been considered as home medicine since time immemorial. It is one of the plant products with highest total flavonoid content and these compounds are responsible for the distinctive taste and color of tea and also the health benefits associated with consumption of tea [5-20]. Polyphenols in tea are secondary metabolites of plants and are generally involved in defense against ultraviolet radiation or aggression by pathogens. Polyphenols may be classified into different groups as a function of the number of phenol rings that they contain and on the basis of structural elements that bind another [21]. The main classes of polyphenols found in tea include phenolic acids, flavonoids, and lignans. Gt and Bt differ in

\section{More Information}

*Address for Correspondence: Gargi Sen, Associate Professor, Department of Optometry $\&$ Vision Science, NSHM College of Management \& Technology, Kolkata, India Tel: 8910323015; Email: sengargi@hotmail.com; gargi.sen@nshm.com

Submitted: 24 February 2020

Approved: 09 March 2020

Published: 10 March 2020

How to cite this article: Sen G, Sarkar N, Nath M, Maity S. Bioactive components of tea. Arch Food Nutr Sci. 2020; 4: 001-009.

DOI: 10.29328/journal.afns. 1001020

Copyright: ( 2020 Sen G, et al. This is an open access article distributed under the Creative Commons Attribution License, which permits unrestricted use, distribution, and reproduction in any medium, provided the original work is properly cited.

Abbreviation: BT: Black Tea; GT: Green Tea; Tf: Theflavins; Tr: Thearubigins; ECG: Epicatechin 3-Gallate; EGCG: EGC 3-Gallate; EC: Epicatechin; EGC: Epigallocatechin

Check for updates

OPEN ACCESS their chemistry, only because of their processing methods but not in leaves itself. The bioactive components in both type of tea has been summarized in table 1 . Thus, which type of tea is superior in terms of health benefits, is a question of much interest. Therefore, this review was aimed at evaluating the health benefits of both types of tea with respect to their mechanism of pharmacological action.

\section{The Key players - Flavanols}

Reactive oxygen species (ROS) and free radicals can cause severe damage to the normal cells of the body. These damages can be to the DNA, proteins, and other biological macromolecules, thereby causing pathological changes in the cellular environment leading to a wide variety of chronic diseases. There are numerous studies that reveal that these diseases are mediated by oxidative stress and imbalance between prooxidant and antioxidant factors. Antioxidants play a pivotal role in preventing or slowing the progression of these conditions. In the last decade, there has been much interest in the potential health benefits of tea polyphenols as antioxidant. Epidemiological studies and associated metaanalyses strongly suggest that long term consumption of diets rich in tea polyphenols offer protection against development of cancers, cardiovascular diseases, diabetes, osteoporosis 


\begin{tabular}{|c|c|c|c|}
\hline \multicolumn{1}{|c|}{$\begin{array}{c}\text { Table 1: Major bioactive components of tea. } \\
\text { SI No }\end{array}$} & Source & Form & Compounds \\
\hline 1 & Green tea and Black tea & Flavonol (Monomer) & Catechin, Epicatechin, Epicatechin gallate, Epigallocatechin and Epigallocatechin gallate \\
\hline 2 & Black tea & Flavanol (Dimer) & Theaflavin,Theaflavin3gallate, Theaflavin 3 O-gallate, Theaflavin 3,3'-digallate \\
\hline 3 & Black tea & Flavonol (Oligomer) & Thearubigin \\
\hline 4 & Green tea and Black tea & Other flavonoid & Quercetin, Kaempferol, Myricetin \\
\hline 5 & Green tea and Black tea & Amino acid & L theanine, Glutamine Arginine \\
\hline 6 & Green tea and Black tea & Methyl xanthine & Caffeine \\
\hline 7 & Green tea and Black tea & Phytooestrogens & Lignans \\
\hline 8 & Green tea and Black tea & Polysachcharides & Galactose, Arabinose, Rhamnose, Xylose, Galacturonic acid, Mannose, Ribose and Glucuronic acid \\
\hline 9 & Green tea and Black tea & Trace minerals & Copper, Manganese, Iron and Zinc \\
\hline
\end{tabular}

and neurodegenerative \& ocular diseases [22,23]. The phenolic groups in bioactive components of tea can donate an electron to form relatively stable phenoxyl radicals, thereby disrupting the cascade of oxidation reactions in cellular components. The most common bioactive compound found in tea are flavonoids like flavan-3-ols (flavanols or flavans), which are present in relatively large amounts in tea compared to their levels in other foods. The flavan-3-ols create the chemical signature pattern that is distinctive in each type of tea. The flavan-3-ol sub-classes are ranked by degree of polymerization $[5,6,8-10,24]$. The catechins are monomers (catechin, epicatechin, epicatechin gallate, epigallocatechin, and epigallocatechin gallate), the $\mathrm{Tfs}$ are dimers (theaflavin, Tf1, theaflavin 3-gallate, Tf2A, theaflavin 30 -gallate, Tf2B, theaflavin 3, 3'-digallate, Tf3), and Tr are oligomers [25]. Gt is rich in monomeric catechins but lack flavanols in dimeric and oligomeric form.

\section{Flavonoids}

Flavonoids found in Gt and Bt include flavonols like quercetin, kaempferol, myricetin [26]. Flavonoids are indispensable components in variety of nutraceuticals because of their anti-inflammatory, anti-oxidative properties coupled with their capacity to modulate various cell signaling. These flavonoids possess numerous health benefits and further research on their therapeutic potential needs to be explored. Unlike flavanols, flavonoids are usually present in tea as glycosides.

\section{Antioxidant property}

Antioxidant property of Gt lies in the monomeric catechins either with or without galloyl moiety. Although Bt contains much lower concentrations of monomeric catechins than $\mathrm{Gt}$, it is generally believed that dimeric or oligomeric catechins contribute greatly to antioxidant action of $\mathrm{Bt}$ [27]. Consumption of catechins by humans either in its monomeric form or after its epimerization results in modest transient increase in the total antioxidant capacity of plasma, measured through ferric-reducing antioxidant potential (FRAP), oxygen radical absorbance capacity (ORAC), or Trolox-equivalent antioxidant capacity (TEAC) assays [28-30]. The studies comparing the antioxidant activities of dimeric and monomeric catechin had revealed that all catechins and Tf inhibited $\mathrm{Cu}^{+2}$-mediated LDL oxidation in the order: $\mathrm{Tf}_{3}>\mathrm{ECG}>\mathrm{EGCG} \geq \mathrm{TF}_{2} \mathrm{~B} \geq \mathrm{TF}_{2} \mathrm{~A}>\mathrm{TF}_{1} \geq$
EC > EGC [31-34]. Examination of the scavenging effects of tea catechins and their glycosides on free radicals had revealed that the presence of at least an ortho-dihydroxyl group in the $\mathrm{B}$ ring and a galloyl moiety at the 3 position was important in maintaining the effectiveness of the radical scavenging ability [35,36]. Yoshino, et al. [37] had also showed that Gt and Bt infusions have almost similar antioxidant activities in rat liver homogenate. The most important catechin oxidation products in Bt are $\mathrm{Tf}$ and its mono and digallates [38]. Tfs possesses a characteristic benzotropolone moiety, which is produced by condensation between a catechol-type B-ring of EC and a pyrogallol-type B-ring of EGC [39]. TFs, are formed via the co-oxidation of pairs of epimerized catechins, one with a vic-trihydroxyphenyl moiety, and the other with an orthodihydroxyphenyl structure. Apart from epimerized catechins are four main Tf derivatives that reserve two Arings, two C-rings from their precursors and possess a characteristic element of the fused seven-member benzotropolone ring [40]. The benzotropolone moiety of Tfs play an important role in affording antioxidant protection for the preferred oxidation site for electron donation because of the existence of resonance forms [41]. Tf radicals have a higher reduction potential than the tea catechin EGCG, Tfs have significantly higher reaction rates with superoxide radicals than EGCG $[42,43]$. It has been suggested that the existence of resonance form in the benzotropolone moiety might be responsible for electron donation $[40,41]$ and it might play an important role in affording antioxidant protection for the preferred oxidation site in the oxidant models of 2,2-diphenyl-1- picrylhydrazyl (DPPH) and hydrogen peroxide. Another important aspect of polyphenols is that the gallated catechins have lower gap energies between the HOMO and LUMO orbitals than those without galloyl moiety. Thus the carbon atoms of galloyl moiety has higher susceptibility toward nucleophilic attack. The antioxidant activity of Tfs were more effective than glutathione (GSH), L(+)-ascorbic (AsA), dlN- tocopherol, butylated hydroxytoluene (BHT), and butyl hydroxyanisole (BHA) in in-vitro peroxidation of rat liver homogenate induced by tert-butyl hydroperoxide (BHP) [42]. Both Bt and Gt have monomeric gallated catechins of the flavanol class and EGCG is the precursor of Tf3 [43] which has the most positive effect in scavenging free radicals [44]. The effectiveness of Tf3 was increased by esterification with gallate [45]. The higher the number of phenyl hydroxyl groups in Tf derivatives the more 
it can interact with ROS and this and benzotropolone moiety might have enhanced the scavenging of the $\cdot \mathrm{O}_{2}, \mathrm{H}_{2} \mathrm{O}_{2}$, and $\cdot \mathrm{OH}$ in in vitro models [43]. The relation of the amount of metal ions in living cells to the oxidation of lipid, the ability to chelate metal ions with Tfs are also important while evaluating its health benefits [46]. Catechins in monomeric or dimeric form can prevent the peroxidation of lipid effectively by cutting off the chain reaction in oxidation of lipid [45].

Trs are known to be heterogeneous polymers of flavan-3ols and flavan-3-ol gallates and their bonds are presumably present at C-4, C-6, C-8, C- $2^{\prime}, \mathrm{C}-5^{\prime}$, and $\mathrm{C}-6^{\prime}$ in the flavan-3-ol unit [47]. The MALDI-TOF results from a more recent study reveal that molecular weight of Trs are not over $2100 \mathrm{Da}$ and these oligomers of catechins in which the 3-OH group is more and less esterified by gallic acid [48]. Tfs and Trs like their major precursor catechins are capable to eliminate free radicals, which is mainly due to the contribution of the residue of the active phenolic hydroxyl groups and benzotropolone groups at the Tr molecule [42].

Catechin in dimerized form, prevents DNA damage by suppressing oxidative stress and inhibiting cytochrome P450 1A1 and other oxidant enzymes under in vitro conditions [49]. Tf ameliorates cerebral injury through anti-inflammatory effects and modulation of signal transducer and activator of transcription (STAT)-1 [50]. Tf targets miRNA-128-3p and leading to the activation of Nrf2 pathway thereby reducing the oxidative stress [51].

Increased expression of inducible nitric oxide synthase (iNOS) and subsequent production of large amounts of nitric oxide results in its reaction with superoxide to form peroxynitrite $_{2}$ and other NO-derived oxidants capable of damaging DNA, proteins and contributes to vascular failure and end-organ damage during endotoxemia and to diseases such as asthma, short- and long-term lung disease, septic shock and other diseases [52], ulcerative colitis, and Crohn's disease [53]. Infusions prepared from Gt, Bt and individual tea polyphenols can suppress iNOS gene expression and iNOS activity in cultured macrophages [54,55]. Pharmacological suppression of iNOSdependent NO production might be helpful in the treatment and prevention of chronic diseases [56].

Tea polyphenols can also inhibit the formation of ROS by inhibiting the enzyme, xanthine oxidase which catalyzes the oxidation of both hypoxanthine and xanthine to uric acid, while reducing $\mathrm{O}_{2}$ to $\mathrm{O}_{2}{ }_{2}^{-}$and $\mathrm{H}_{2} \mathrm{O}_{2}$ [57]. Apart from Monomeric and dimeric catechins Quercetin found in both Bt and Gt have strong ability to sequester free radicals and bind transition metal ions [58]. Beyond antioxidant activity: as modulators of cell signaling. Despite significant advances in our understanding of the biology of tea polyphenols, they are still mistakenly regarded simply as antioxidants. The evidences suggest that their beneficial effects involve decreases in oxidative/ inflammatory stress signaling, increases in protective signaling and neuro hormetic effects leading to the expression of genes that encode antioxidant enzymes, phase- 2 enzymes, neurotrophic factors, and cytoprotective proteins $[59,60]$. Specific examples of such pathways include the sirtuin- FoxO pathway, the NF- $\kappa$ B pathway, and the Nrf-2/ARE pathway [61].

The mechanism(s) of the inhibitory effects of Gt or Bt on carcinogenesis are related to inhibition of NADPHcytochrome P450 reductase; inhibition of $\mathrm{N}$ - $\mathrm{O}$-acetyltransferase; induction of CYP1A2 and UDP-glucuronosyl transferase (leading to increased metabolism of IQ and rapid elimination of detoxification products in the urine); and electrophile scavenging/degradation [62]. The antioxidant properties of tea also might be important during the post initiation phase of carcinogenesis $[63,64]$.

Bt and Gt can help fight cavities and prevent gum disease [65]. Tea polyphenols suppressed the growth of cavity-causing bacteria in plaque and reduced acid production levels [66]. Tea polyphenols also inhibited an enzyme produced by the bacteria, glucosyltransferase, thus preventing the formation of the matrix material by which dental plaque adheres to tooth surfaces [67]. In addition, the size and stickiness of dental plaque were reduced because certain bacteria, when exposed to black tea, lost their ability to form aggregates with other bacteria $[65,68]$.

Monomeric catechins and flavonoids, found in Gt can maintain stable mitochondrial membrane potential $(\Delta \Psi \mathrm{m})$ of target cells and decrease the lens epithelial cell death rate under high glucose [69]. Tea polyphenol containing ophthalmic gel could maintain stable $\Delta \Psi \mathrm{m}$, reduce the generation of ROS, and prevent lenticular epithelial cells from apoptosis in experimental model and possesses great potential in clinical practice. IgE and FceRI are essential in the development of allergic diseases. Studies revealed that tea polyphenol could suppress the expression on the Fc epsilon receptor I (FceRI) by highly associating with plasma membrane microdomains and lipid. Studies confirmed that EGCG attenuated the mucus production and the MAPK expression in an asthma modelmouse [70].

Ocular hypersensitivity including contact dermatitis and corneal allograft rejection are major type IV allergies where new formulations are required. It has been found that $\mathrm{Tf}$ is involved in inhibition of the alterations of cytokines and maintenance of antioxidant status in animals with type IV allergies [71]. Further studies in this direction is required for commercial preparation of drugs. Flavonoid component has a ability in inhibiting Lyn/PLC $\gamma /$ IP3R-Ca ${ }^{2+}$, Lyn/ERK1/2, and Lyn/NF- $\kappa B$ signaling and there by dampening the inflammatory response during allergic conjunctivitis [72].

Many beneficial physiological and pharmacological effects have been ascribed to tea consumption is at least in part, related to the inhibition of gelatinases involved in both tumor 
invasion and neo- angiogenesis (the growth of new blood vessels into a tumor) [73]. Some aggressive bacterial strains produce high amounts of gelatinases that contribute to their pathogenesis green tea polyphenols have the ability to inhibit bacterial gelatinases [74]. Some important flavonoid found in tea improves retinal ganglion cell survival and function in glaucomatous neurodegeneration however more studies in this area is required [75].

Aprodrugofteapolyphenolalleviated thehypoxia-inducible factor-1 $\alpha$ (HIF-1 $\alpha) /$ vascular endothelial growth factor (VEGF)/VEGF receptor 2 (VEGFR2) pathway that contributes to the pathogenesis of choroidal neovascularization $[76,77]$. However, studies with Bt polyphenols are lacking.

Reports suggest, tea compounds mimic the effect of insulin signaling to FOX01a and PEPCK, key downstream effectors of cellular insulin/longevity signaling [78]. Bt and Gt polyphenols also suppress certain genes in the liver that are responsible for glucose metabolism [79]. Bioactive components found in tea including kaempferol, myricetin, quercetin, ECG, Tf3, Tf2B, Tf2A have been reported as anti-HIV-1 compounds. Their high biological activity and low toxicity tea polyphenolics represent a valuable natural source of molecules that might be favorable to HIV patients due to enhanced lymphocyte proliferation, which could restore disturbances in T-cell homeostasis [80]. Molecular docking and molecular dynamic simulation studies have revealed that Tf3, is one of the most potent gp41 inhibitor [81]. A common conclusion drawn from scientific evidence is conversion of monomeric catechins during fermentation to dimeric and oligomeric form in Bt does not diminish its therapeutic and antioxidant potency of tea. Bt has more or less has similar ability as GT to be considered as an adjuvant in therapeutics. The health benefits of bioactive components of tea has been shown in figure 1.

\section{Other important bioactive components of tea}

Caffeine: Caffeine another component of Gt and Bt that may contribute to the inhibitory effect of both these beverages

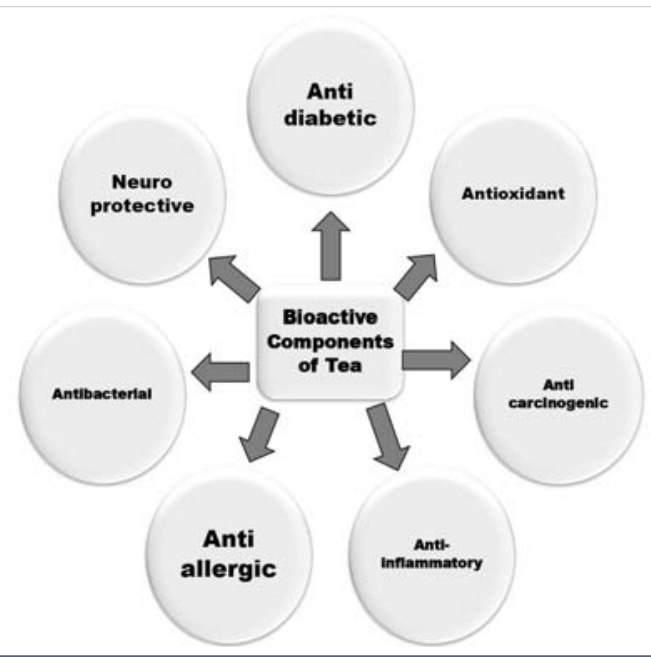

Figure 1: Health benefits of bioactive components of tea. on tumorigenesis. Teas containing more leaf buds tend to contain more caffeine, whereas teas made of mature leaves and stems tend to contain less caffeine. The processing also affects caffeine content [82]. Tea leaves contain 3\% caffeine by weight, although this can range from $1.4 \%$ to $4.5 \%$. The amount of caffeine present varies amongst Bt and Gt. Caffeine has numerous therapeutic effects. It targets the central nervous system, stimulates the cardiovascular and digestive system and is known for alleviating mental fatigue. The result of caffeine on the central nervous system is mood elevation, alertness, increased focus and cognitive clarity. Caffeine is also credited for aiding with metabolic functioning and is one ingredient used in weight loss supplements. Caffeine is touted as an aid for increasing energy, which influences fat burning. Additionally, the diuretic effect of caffeine prompts frequent elimination of waste from the digestive system. Caffeine has also shown a protective effect against heart disease when used daily in moderation [83]. Recent studies have shown that topical administration of chitinase inhibitors, caffeine and dexamethasone in combination produced a remarkable reduction of inflammatory signs. Caffeine has more antiinflammatory property than the chitinase inhibitors and significantly reduces acidic mammalian chitinase activity in tears [78].

Amino acids: In $\mathrm{Gt}$ and $\mathrm{Bt}$, L-theanine is one of the most important amino acid and it accounts for almost 50\% of the total free amino acids found in tea. It was first discovered in an aqueous extract of Gt, later it was reported in Bt [84]. Reports suggest that theanine is synthesized in the tea roots and then proceeded to the developing shoot tips under the catalytic activity of a specific enzyme, L-glutamate ethylamine ligase and using the amino acid alanine as the precursor of ethyl-amide in presence of light [85]. The chemical structure of L-theanine is gamma-ethyl amide of glutamic acid. The amount of theanine present in tea is dependent upon the cultivation process, growing conditions and type of tea [86]. Reports suggest that black tea contains the highest quantity of theanine. Darjeeling black tea contains the highest quantity of theanine (250 mg/100 gms). Although caffeine can have certain negative effects on anxiety disorders, studies reveal that L-theanine neutralizes negative effects of caffeine without reducing its mind- energizing, fat-burning features $[87,88]$.

Amino acids other than theanine found in Gt and Bt include conditionally essential amino acids glutamine and arginine. Under stress conditions, these amino acids become essential and it has to be taken as food or supplements. Gt and Bt also contains amino acids like asparagine, and serine.

Lignans: Gt and Bt contain lignans, which are compounds that form the building blocks of plant cell walls. Lignans are phytoestrogens that help regulate the body's estrogen production. Lignans are converted by intestinal bacteria into the enterolignans, enterodiol and enterolactone. Enterolactone, the primary lignan metabolite circulates in 
the blood \& produces weak estrogenic activity and possess several biological activities. Studies have shown enterolactone helps to reduce risk of breast, prostate and colon cancers, and cardiovascular diseases. Moreover, lignans can support healthy weight and glucose metabolism, reducing the risk of insulin resistance, metabolic syndrome and diabetes. Although observations that drinking tea, appears to be protective against osteoporosis in older women $[62,89]$. This necessitates further investigation.

Tea polysaccharides: Tea polysaccharides (soluble fibers) were found to be mostly glycoconjugates in which a protein carries one or more carbohydrate chains covalently attached to a polypeptide backbone, usually via N- or O- linkages [90]. Reports suggest polysaccharides present in Gt and Bt blunts the spike in blood sugar level after meal and retard the absorption of glucose and may thus be beneficial to people with diabetes [91-93]. Interestingly, the polysaccharides in Bt also seemed to possess the strongest ability to mop up free radicals, which are believed to play a role in the onset of numerous cancers. The Bt was found to contain lower molecular weight polysaccharides (3.8 - $32.7 \mathrm{kDa}$ ) than $\mathrm{Gt}$ 9.2 - $251.5 \mathrm{kDa}$. Studies show that the Bt polysaccharides showed a dose-dependent effect on $\alpha$-glucosidase inhibitory activity [94]. $\alpha$-glucosidase inhibitors are often considered as oral anti-diabetic drugs that prevents the breakdown of carbohydrates. Studies suggest that Gt polysaccharides hardly inhibited $\alpha$-glucosidase activity under similar conditions [94]. A mathematical analysis of data from 50 Countries reveal that the prevalence of Type 2 diabetes is low in countries where people consume Bt regularly [95]. The scavenging rates of Gt polysaccharides and Bt polysaccharides on DPPH radicals were 47.9\%, and 61.7\%, respectively [95]. Deoxyribose assay, the photo-reduction of NBT assay and the lipid peroxidation inhibition studies indicated Tea Polysaccharide of molecular weight $26.8 \mathrm{kD}, 11.8 \mathrm{kD}, 4.2 \mathrm{kD}$ exhibited the highest antioxidant activities [96]. While detailed studies on cause- bioavailability - effect relationship between Gt and Bt drinking and various diseases are yet to be confirmed, the scientific findings are consistent with a number of biological, physiological, epidemiological and clinical studies suggesting that Gt and Bt have a positive effect on human health.

Trace elements: Tea (Bt and $\mathrm{Gt}$ ) is rich in essential trace elements, which might play an important role in ionic homeostasis in the physiological system. Among the minerals and essential trace elements, $\mathrm{Ca}, \mathrm{Na}, \mathrm{K}, \mathrm{Mg}$, and $\mathrm{Mn}$ are present in tea leaves at $\mathrm{g} / \mathrm{kg}$ level, while $\mathrm{Cr}, \mathrm{Fe}, \mathrm{Co}, \mathrm{Ni}, \mathrm{Cu}, \mathrm{Zn}$ are present at $\mathrm{mg} / \mathrm{kg}$ level. Reports suggest that the presence of trace elements in green tea is lower than that of black tea. Besides essential macro- and microelements, Camellia sinensis strongly accumulate aluminum. Aluminum in most of its forms has no harmful effect on living organisms. However, under certain conditions aluminum might form toxic species [97]. However, these studies appear to have major limitation and may need more detailed investigations.
Bioavailability: The worldwide popularity of tea and the absence of toxicity as a natural dietary agent, has made tea an excellent candidate for dietary prevention of chronic diseases [98]. Results from various studies show that the bioavailability of many important tea polyphenolics is low. The poor bioavailability of EGCG, theaflavins, and thearubigins may be explained by Lipinski's Rule of 5 , which is based on the ability of a molecule to pass through transient pores formed in the plasma membrane by the movement of the phospholipid acyl tails and also a molecule's ability to form hydrogen bonds. Many of the mechanistic studies of the tea polyphenolics have been conducted on cell lines. But it is unlikely that the concentration of polyphenol used in these experiments can be obtained in target tissues other than the skin and GI tract under in vivo conditions. So, correlating mechanistic data observed in vitro with that found in vivo should be done with careful consideration of the poor bioavailability of the tea polyphenols.

Glucuronidation, sulfation, and methylation represent the major metabolic pathways for tea polyphenolics [99]. There are species and tissue-specific differences in tea polyphenolics glucuronidation, with humans and mice being more similar than humans and rats $[99,100]$. Methylated catechins have been observed in the rat bile of the rat following oral EGCG administration. In humans, EGC is detected mainly as the glucuronidation form or sulfated form with only a small amount present as the free form $[100,101]$. Methylation of EGC also occurs in humans leading to the formation of glucuronide or sulfate conjugate. The sulfated form of EC is more abundant than the glucuronidation form [101] while EGCG is present mainly in the free form in the plasma [102]. In addition to these conjugation reactions, the tea catechins undergo metabolism in the gut to form the ring fission products gamma valerolactone [103] which may be further broken down by gut flora to phenylacetic and phenylpropionic acids.

Recent studies reveal that polyphenols interact with model membranes in a structure-dependent manner. Liposomes showed morphological changes with higher percentage in the presence of Tf- $2>$ Tf $>$ EGCG $>$ GC corresponding to the number of phenolic gallate groups and hydroxyl groups in polyphenols influencing how the polyphenols interact with the membrane, following initial H-bond driven interaction. These polyphenols mainly affected hydrophilic region of lipid bilayers [104].

Decaffeinated tea supplements provide large doses of polyphenols without the unwanted side effects of caffeine. Studies reveal polyphenols administered in the form of solid tea showed enhanced bioavailability compared with that of Gt or Bt. Administration of Gt and Bt solids led to significant increase in antioxidant capacity [105]. Flavanol metabolite formation may have contributed to the antioxidant effect and this issue deserves further investigation. However, efforts to translate the results of in vitro and animal studies to human 
interventions have met with limited success [106]. This may be due to the fact that during in vitro studies, the cells are exposed to supra-physiologic concentrations of tea catechins and there is limited information on the bioavailability of tea flavanols post consumption of tea brew $[107,108]$. Use of nanotechnology, improves the bioavailability of tea bioactive components and consequently enhance the bioactivity [109].

\section{Conclusion}

It is also likely that tea components by their ability to control intracellular signaling cascades that target multiple signal transduction pathways, are involved in the inhibition of various chronic diseases. Among the numerous mechanisms proposed, it is also important to further investigate, which are the primary and subsequent events. The relative importance of these pathways needs to be determined under in vivo conditions. The flavonols and flavonoids present in Gt and Bt interact synergistically in their disease modifying actions. However, the absorption rate of black tea polyphenols is higher than that of green tea polyphenols. Novel strategies to enhance the absorption of tea polyphenols and subsequently improve their bioavailability, should be probed. However, it remains the healthiest beverage amongst all.

\section{References}

1. Naghma K, Hasan M. Tea and Health: Studies in Humans Des. Curr Pharm. 2013; 19: 6141-6147.

PubMed: https://www.ncbi.nlm.nih.gov/pubmed/23448443

2. Koushik B, Rajeev KS, Baishakhi D, Bijoy CG, Prakash K, et al. Chemometrics Based Extraction of Polyphenolics from Fresh Tea Leaves and Processed Tea Showing In-Silico-ocking and Antioxidative Theronostic Dietary Adjuvant in Alzheimer. Indo Global J Pharmaceutical Sci. 2015.

3. Lee MJ, Maliakal P, Chen L, Meng X, Bondoc FY, et al. Pharmacokinetics of tea catechins after ingestion of green tea and (-)-epigallocatechin3-gallate by humans: formation of different metabolites and individual variability. Cancer Epidemiol Biomarkers Prev. 2002; 11: 1025-1032. PubMed: https://www.ncbi.nlm.nih.gov/pubmed/12376503

4. Over C, Dora MB, Norma SK, Camillo R, Per-OB, et al. The unique cytoarchitecture of human pancreatic islets has implications for islet cell function. Proc Natl Acad Sci USA. 2006; 103: 2334-2339.

PubMed: https://www.ncbi.nlm.nih.gov/pubmed/16461897

5. Mukhtar H, Ahmad N. Green tea in chemoprevention of cancer. Toxico Sci. 1999; 5: 111-117.

PubMed: https://www.ncbi.nlm.nih.gov/pubmed/10630599

6. Bushman JL. Green tea and cancer in humans: a review of the literature Nutr Cancer. 1998; 31: 151-159.

PubMed: https://www.ncbi.nlm.nih.gov/pubmed/9795966

7. Susie L, Yung HK, Richard AH. Green tea: Biochemical and biological basis for health benefits. Vitam Horm. 2001; 62: 1-94.

PubMed: https://www.ncbi.nlm.nih.gov/pubmed/11345896

8. Mikhail AB, Nina IS. The biochemistry and technology of tea manufacture. Crit Rev Food Sci Nutr. 1998; 12: 303-370.

PubMed: https://www.ncbi.nlm.nih.gov/pubmed/6996921

9. Lenore K, Karen GCW, Susan S, Frans JK. Tea and cancer prevention: An evaluation of the epidemiologic literature. Nutr Cancer. 2009; 27: 1-13. PubMed: https://www.ncbi.nlm.nih.gov/pubmed/8970175
10. Kuroda $\mathrm{Y}$, Hara Y. Antimutagenic and anticarcinogenic activity of tea polyphenols. Mutat Res. 1999; 436: 69-97.

PubMed: https://www.ncbi.nlm.nih.gov/pubmed/9878691

11. Middleton E Jr, Kandaswami C, Theoharides TC. The effects of plant flavonoids on mammalian cells: implications for inflammation, heart disease, and cancer. Pharmacol Rev. 2000; 52: 673-751. PubMed: https://www.ncbi.nlm.nih.gov/pubmed/11121513

12. Mukhtar $\mathrm{H}$, Ahmad N. Tea polyphenols: prevention of cancer and optimizing health. Am J Clin Nutr. 2000; 71: 673-751.

PubMed: https://www.ncbi.nlm.nih.gov/pubmed/10837321

13. Nijveldt RJ, van Nood E, van Hoorn DE, Boelens PG, van Norren $K$, et al. Flavonoids: a review of probable mechanisms of action and potential applications. Am J Clin Nutr. 2001; 74: 418-425.

PubMed: https://www.ncbi.nlm.nih.gov/pubmed/11566638

14. Riemersma RA, Rice ECA, Tyrrell RM, Clifford MN, Lean MEJ. Tea flavonoids and cardiovascular health. QJM. 2001; 94: 277-282. PubMed: https://www.ncbi.nlm.nih.gov/pubmed/11353103

15. Stoner GD, Mukhtar H. Polyphenols as cancer chemopreventive agents. J Cell Biochem Suppl. 995; 22: 169-180. PubMed: https://www.ncbi.nlm.nih.gov/pubmed/8538195

16. Huafu W, Gordon J, Provan, KH. Tea flavonoids: their functions, utilization and analysis. Trends Food Sci Technol. 2000; 11: 152-160.

17. John HW. Second International Scientific Symposium on Tea and Human Health. Proc Soc Exp Biol Med. 1999; 220: 193-194.

PubMed: https://www.ncbi.nlm.nih.gov/pubmed/10202385

18. Douglas AB, Sheila AW, Liesbeth $C M$. The chemistry of tea flavonoids. 2009; 693-704.

19. Chung SY. Inhibition of carcinogenesis by tea. 1997; 389: 134-135.

20. Yang CS, Landau JM. Effects of tea consumption on nutrition and health. J Nutr. 2000; 2: 2409-2412.

PubMed: https://www.ncbi.nlm.nih.gov/pubmed/11015465

21. Hung YL. The Structural Characteristics of Green Tea Polyphenols on Lipopolysaccharide-Stimulated RAW Cells. J Nutri Biol. 2018; 2: 151-157.

22. Vauzour D, Vafeiadou K, Rodriguez-Mateos A, Rendeiro C, Spencer JPE. The neuroprotective potential of flavonoids: a multiplicity of effects. Genes Nutr. 2008; 3: 115-126.

PubMed: https://www.ncbi.nlm.nih.gov/pubmed/18937002

23. Pandey KB, Rizvi SI. Plant Polyphenols as Dietary Antioxidants in Human Health and Disease. Oxid Med Cell Longev. 2009; 2: 270-278. PubMed: https://www.ncbi.nlm.nih.gov/pubmed/20716914

24. Fujiki H. Two stages of cancer prevention with green tea. J Cancer Res Clin Oncol. 1999; 125: 589-597.

PubMed: https://www.ncbi.nlm.nih.gov/pubmed/10541965

25. Peterson J. Major flavonoids in dry tea. J Food Comp Anal. 2005; 18 487-501.

26. Michael GL, Hertog PC, Hollman B, Van de P, Agric J. Content of potentially anticarcinogenic flavonoids of tea infusions, wines, and fruit juices. Food Chem. 1993; 41-48.

27. Krishnan R, Maru G. Isolation and analyses of polymeric polyphenol fractions from Black tea. Food Chem. 2006; 331-340.

28. Leenen R, Roodenburg AJC, Tijburg LBM, Wiseman SA. A single dose of tea with or without milk increases plasma antioxidant activity in humans. Eur J Clin Nutr. 2000; 54: 87-92.

PubMed: https://www.ncbi.nlm.nih.gov/pubmed/10694777

29. Jin ZX, Sai YVY, Qi C, Yu H, Zhen YC. Comparison of antioxidant activity and bioavailability of tea epicatechins with their epimers. $\mathrm{Br}$ J Nutr. 2004; 91: 873- 881.

PubMed: https://www.ncbi.nlm.nih.gov/pubmed/15182391 
30. Alexander $Y$, Yakov Y, Boris N. Determination of Antioxidant Activity in Tea Extracts, and Their total antioxidant content. Am J Biom Sci. 2011.

31. Ya LS, Lai KL, Yu H, Zhen YC. Stability of tea theaflavins and catechins. Food Chem. 2003; 83: 189-195.

32. Jou AL, Wei CY, Ju YH. An assessment of genetic relationships in cultivated tea clones and native wild tea in Taiwan using RAPD and ISSR markers. Bot Bull. 2000; 93-100.

33. Łuczaj W, Skrzydlewska E. Antioxidative properties of black tea. Prev Med. 2005; 910-918.

PubMed: https://www.ncbi.nlm.nih.gov/pubmed/15850895

34. Sheila AW, Douglas AB, Balz F. Antioxidants in tea: Critical Reviews in Food Science and Nutrition. Tea and Health. 1997; 37.

35. Vasundhara S, Honnaiah VKL, Jagan MR. Influence of milk and sugar on antioxidant potential of black tea. Research International. 2008; 124-129.

36. Eric WCC, Eu YS, Pei PT, Yon PL. Antioxidant and antibacterial properties of green, black, and herbal teas of Camellia sinensis. Pharmacognosy Res. 2011; 3: 266-272.

PubMed: https://www.ncbi.nlm.nih.gov/pubmed/22224051

37. Maki H, Katsumi Y. Liquid Crystalline Behavior and Optical Properties of Poly (2,5-dinonyloxy-p-phenylenevinylene). Japanese Journal of Applied Physics. 1994; 33.

38. Leung LK, Su Y, Chen R, Zhang Z, Huang $Y$, et al. Theaflavins in black tea and catechins in green tea are equally effective antioxidants. $J$ Nutr. 2001; 131: 2248-2251.

PubMed: https://www.ncbi.nlm.nih.gov/pubmed/11533262

39. Hong L, Xiaofeng M, Chuan L, Shengmin S, Christopher $P$, et al. Glucuronides of Tea Catechins: Enzymology of Biosynthesis and Biological Activities. Drug Metab Dispos. 2003; 31: 452461.

PubMed: https://www.ncbi.nlm.nih.gov/pubmed/12642472

40. Jin WJ, Chih YL, Shiming LS, Sang CYW, Ang TM. et al. Agric: Stability of Black Tea Polyphenol, Theaflavin, and Identification of Theanaphthoquinone as Its Major Radical Reaction Product. Food Chem. 2005; 53; 6146-6150.

PubMed: https://www.ncbi.nlm.nih.gov/pubmed/16029009

41. Slobodan VJ, Micheal GS. Antioxidants in Nutrition. Ann New York Acad Sci. 2000; 899: 326-334.

42. Kyoji Y, Isao T, Mitsuaki S, Itaro O, Yukihiko H, et al. Effects of long-term dietary supplement of tea polyphenols on lipid peroxide levels in rats. Age. 1994; 17: 79-85.

43. Xinling $Y$, Jun F, Zhengguo LL, Yu WL, Walter JF. Tea Classification Based on Artificial Olfaction Using Bionic Olfactory Neural Network. Int Sym Neur Net. 2006; 343-348.

44. Agarwal R, Mukhtar H. Cancer chemoprevention by polyphenols in green tea and artichoke. Adv Exp Med Biol. 1996; 401: 3550. PubMed: https://www.ncbi.nlm.nih.gov/pubmed/8886125

45. Samir M, Tanmay SN, Koushik B, Adinpunya M, Ghosh BC, et al Protective effect of tea against copper $(\mathrm{Cu})$ toxicity in erythrocyte. International Journal of Tea Science. 2013; 12-25.

46. Xin M, Yuan YW, Xiao M, You YT. Antagonism of phenanthrene cytotoxicity for human embryo lung fibroblast cell line HFL-I by green tea polyphenols. Environ Pollut. 2011; 159: 164-168. PubMed: https://www.ncbi.nlm.nih.gov/pubmed/20932619

47. Miller NJ, Castelluccio C, Tijburg L, Rice EC. The antioxidant properties of theaflavins and their gallate esters--radical scavengers or metal chelators? FEBS Lett. 1996; 19: 40-44.

PubMed: https://www.ncbi.nlm.nih.gov/pubmed/8769311
48. Tetsuo O, Mari K, Keiko M, Osamu N. Elucidation of the Partial Structure of Polymeric Thearubigins from Black Tea by Chemical Degradation. 2014; 60: 2023-2027.

49. James WD, Michael NC, Jacek O, Nikolai K. The chemistry of low molecular weight black tea polyphenols. Nat Prod Rep. 2010. 27: 417-462 PubMed: https://www.ncbi.nlm.nih.gov/pubmed/20179879

50. Yudong Z, Xiaojun Y, Carlo C, Ravipudi VR, Shuihua W. Tea Category Identification Using a Novel Fractional Fourier Entropy and Jaya Algorithm. 2016; 18.

51. Huimei C, Yangyang D, Yeyun L, Daxiang L, Chuanyi $P$, et al Physiological and cellular responses to fluoride stree in tea (Camellia sinensis) leaves. Acta Physiologiae Plantrum. 2016; 38.

52. Junhua L, Rafael RG, John S, Lei F. Habitual tea drinking modulates brain efficiency: evidence from brain connectivity evaluation. Aging 2019; 11: 3876-3890.

PubMed: https://www.ncbi.nlm.nih.gov/pubmed/31209186

53. Bogdan C. Nitric oxide and the immune response. Nat Immunol. 2001 907-916.

54. Guslandi. Nitric oxide and inflammatory bowel diseases. Eur J Clin Inv. 2001.

55. Anasuya S, Amar B. Black Tea Is a Powerful Chemopreventor of Reactive Oxygen and Nitrogen Species: Comparison with Its Individual Catechin Constituents and Green Tea. Biochem Biophys Res Commun. 2001; 284: 173-178.

PubMed: https://www.ncbi.nlm.nih.gov/pubmed/11374887

56. Kim ES, Liang YR, Jin QJ, Sun FJ, Lu YL, et al. Impact of heating on chemical compositions of green tea liquor. Food Chem. 2007; 103 $1263-1267$.

57. Ming X, Genie ED, Legarda S, Joseph L. Production of Vascular Endothelial Growth Factor by Murine Macrophages: Regulation by Hypoxia, Lactate, and the Inducible Nitric Oxide Synthase Pathway. Am J Pathol. 1998: 153: 587-598.

PubMed: https://www.ncbi.nlm.nih.gov/pubmed/9708818

58. Lin CM, Chen CS, Chen CT, Liang YC, Lin JK. Molecular modeling of flavonoids that inhibits xanthine oxidase. Biochem Biophys Res Commun. 2002; 294; 167-172.

PubMed: https://www.ncbi.nlm.nih.gov/pubmed/12054758

59. Alexandra BB. A Review of Quercetin: Chemistry, Antioxidant Properties, and Bioavailability. Journal of Young Investigators. 2009.

60. Gargi S, Biswajit B. Black tea as a part of daily diet: A boon for healthy living. International journal of Tea Science. 2013; 9.

61. David V. Biological Actions and Molecular Mechanisms Underpinning, Their Beneficial Effects. Oxid Med Cell Longev. 2012; 16. PubMed: https://www.ncbi.nlm.nih.gov/pubmed/22701758

62. Trina K, Subhabrata D, Madhumita R, Siddiqi M, Bhattacharya RK. Induction of apoptosis in human leukemia cells by black tea and its polyphenol theaflavin. 2005; 230: 111-121.

PubMed: https://www.ncbi.nlm.nih.gov/pubmed/16253767

63. Sang S, Hou Z, Lambert JD, Yang CS. Redox properties of tea polyphenols and related biological activities. Antioxid Redox Signal. 2005; 7: 1704-1714.

PubMed: https://www.ncbi.nlm.nih.gov/pubmed/16356131

64. Shukla Y, Tanya P. Anticarcimogenic effect of black Tea on pulmonary tumors of Swiss Albino mice. Cancer Letters. 2002; 25: 137-141. PubMed: https://www.ncbi.nlm.nih.gov/pubmed/11804740

65. Lahiry L, Mandal DP, Bhattacharyya A, Sa G, Das T. Cancer prevention by cancer regression and rejuvenation of hostâ $€^{\text {TM }}$ s defense system dual role of tea. Medicinal Properties of tea. 2005. 
66. Sarkar S, Sett P, Chowdhury T, Ganguly DK. Effect of black tea on teeth. J Indian Soc Pedod Prev Dent. 2000; 18: 139-140.

PubMed: https://www.ncbi.nlm.nih.gov/pubmed/11601182

67. Hamidreza A, Ahmad M, Shayan G, Hoomanshafaee, Keyvan S, et al Review of The therapeutic effects of Camellia sinensis (green tea) on oral and periodontal health. J Medi Pla Res. 2011; 5: 5465-5469.

68. Xu X, Zhou XD, Wu CD. Tea catechin epigallocatechin gallate inhibits Streptococcus mutans biofilm formation by suppressing gtf genes. Arch Oral Biol. 2012; 57: 678-683.

PubMed: https://www.ncbi.nlm.nih.gov/pubmed/22169220

69. Hattori M, Kusumoto IT, Namba T, Ishigami T, Hara Y. Effect of tea polyphenols on glucan synthesis by glucosyltransferase from Streptococcus mutans. Chem Pharm Bull. 1990; 38: 717-720.

PubMed: https://www.ncbi.nlm.nih.gov/pubmed/2140716

70. Yali J, Guanjun H, Yun H, Yan B, Lirong L, et al. Tea consumption and risk of Type 2 Diabetes: A Meta-Analysis of Cohort Studies. J Gen Intern Med. 2009; 24: 557-562.

PubMed: https://www.ncbi.nlm.nih.gov/pubmed/19308337

71. Ying Z, Lanting Z, Xiaoyu L, Jiadong $G$, Xin $M$, et al. Formation of $(E)$ nerolidol in tea (Camellia sinensis) leaves exposed to multiple stresses during tea manufacturing. Food Chem. 2017; 231: 78-86.

PubMed: https://www.ncbi.nlm.nih.gov/pubmed/28450026

72. Yoshino K, Yamazaki K, Sano M. Preventive effects of black tea theaflavins against mouse type IV allergy. J Sci Food Agric. 2010; 90: 1983-1987.

PubMed: https://www.ncbi.nlm.nih.gov/pubmed/20597096

73. Ding Y, Li C, Zhang Y, Ma P, Zhao T, et al. Quercetin as a Lyn kinase inhibitor inhibits IgE-mediated allergic conjunctivitis. Food Chem Toxicol. 2020. 135: 110924.

PubMed: https://www.ncbi.nlm.nih.gov/pubmed/31672514

74. Young DJ, Lee ME. Inhibition of tumour invasion and angiogenesis by epigallocatechin gallate (EGCG), a major component of green tea. Int $J$ Exp Pathol. 2001; 82: 309-316.

PubMed: https://www.ncbi.nlm.nih.gov/pubmed/11846837

75. Anna RB, Simona La TM, Gioia B, Spiridione G, Vincenzo E, et al. (-) Epigallocatechin-3-gallate inhibits gelatinase activity of some bacterial isolates from ocular infection, and limits their invasion through gelatin. Biochim Biophys Acta. 2003; 1620: 273-281.

PubMed: https://www.ncbi.nlm.nih.gov/pubmed/12595099

76. Jun Y, Yunqiang Z, Yunqiang Z. Single-Junction Organic Solar Cell with over $15 \%$ Efficiency Using Fused-Ring Acceptor with Electron-Deficient Core. 2019; 3: 1140-1151.

77. Bucolo C, Musumeci M, Maltese A, Drago F, Musumeci S. Effect of chitinase inhibitors on endotoxin-induced uveitis (EIU) in rabbits. Pharmacol Res. 2008; 57: 247-252.

PubMed: https://www.ncbi.nlm.nih.gov/pubmed/18353673

78. Amy RC, Siobhan A, Laura M, Nicola PH, Saurabh D, et al. Black tea polyphenols mimic insulin/insulin-like growth factor-1 signalling to the longevity factor FOX01a. Aging Cell. 2008; 7: 69-77.

PubMed: https://www.ncbi.nlm.nih.gov/pubmed/18005251

79. Kati $H$, Riitta $T$, Isabel BP, Jenna $P$, Marjukka $K$, et al. Impact of Dietary Polyphenols on Carbohydrate Metabolism. Int J Mol Sci. 2010; 13651402.

PubMed: https://www.ncbi.nlm.nih.gov/pubmed/20480025

80. Ziyin Y, Eiji K, Tsuyoshi K, Toshimichi A, Tamaki F, et al. Characterisation of volatile and non-volatile metabolites in etiolated leaves of tea (Camellia sinensis) plants in the dark. Food Chemistry. 2012; 135: 2268-2276.

PubMed: https://www.ncbi.nlm.nih.gov/pubmed/22980801
81. Mostashari RT, Saghaei L, Fassihi A. Gp41 inhibitory activity prediction of theaflavin derivatives using ligand/structure-based virtual screening approaches. Comput Biol Chem. 2019; 78: 119-126. PubMed: https://www.ncbi.nlm.nih.gov/pubmed/30785021

82. Astill C, Birch MR, Dacombe C, Humphrey PG, Martin PT. Factors affecting the caffeine and polyphenol contents of black and green tea infusions. J Agric Food Chem. 2001; 49: 5340-5347

PubMed: https://www.ncbi.nlm.nih.gov/pubmed/11714326

83. Dong US, Young DJ, Kee OC, Min AC, Kee HL, et al. Effect of Drinking Green Tea on Age-Associated Accumulation of Maillard-Type Fluorescence and Carbonyl Groups in Rat Aortic and Skin Collagen. Arch Biochem Biophys. 2015; 3972: 424-429.

PubMed: https://www.ncbi.nlm.nih.gov/pubmed/11795903

84. Emma KK, Mike DA, Paul S.J, Peter JR, Caroline MP. How much theanine in a cup of tea? Effects of tea type and method of preparation. Food Chemistry. 2011; 125: 588594.

85. Vuong QV, Golding JB, Nguyen M, Roach PD. Extraction and isolation of catechins from tea. J Sep Sci. 2010; 33: 3415-3428.

PubMed: https://www.ncbi.nlm.nih.gov/pubmed/21049524

86. Nobre AC, Rao A, Owen GN. L-theanine, a natural constituent in tea, and its effect on mental state. Asia Pac J ClinNutr. 2018; 167-168. PubMed: https://www.ncbi.nlm.nih.gov/pubmed/18296328

87. Kakuda T. Neuroprotective effects of the green tea components theanine and catechins. Biol Pharm Bull. 2002; 1513-1518.

PubMed: https://www.ncbi.nlm.nih.gov/pubmed/12499631

88. Chattopadhyay P, Besra SE, Gomes A, Das M, Sur SM, et al. Antiinflammatory activity of tea (Camellia sinensis) root extract. Life Sci. 2004; 74: 1839-1849.

PubMed: https://www.ncbi.nlm.nih.gov/pubmed/14761665

89. Shao PN, Ming YX. A review on the isolation and structure of tea polysaccharides and their bioactivities. Food Hydrocolloids. 2011; 2: 144-149.

90. Deng Z, Tao B, Li X, He J, Chen Y. Effect of green tea and black tea on the metabolisms of mineral elements in old rats. Biol Trace Elem Res. 1998; 65: 75-86.

PubMed: https://www.ncbi.nlm.nih.gov/pubmed/9877538

91. Chen MJ, Jovanovic A, Taylor R. Utilizing the second meal effect in type 2 disbetes: practical use of a soya-yogurt snack. Diabetes Care. 2010; 2552-2554.

92. Ariel B, Gerard D, Genevieve B, Dominique BG. Relationships between black tea consumption and key health indicators in the world: an ecological study. BMJ Open. 2012; 2 .

PubMed: https://www.ncbi.nlm.nih.gov/pubmed/23138107

93. Takahashi M. Acute ingestion of catechin-rich green tea improves postprandial glucose status and increases serum thioredoxin concentrations in postmenopausal women. Br J Nutr. 2014; 112: 1542-1550. PubMed: https://www.ncbi.nlm.nih.gov/pubmed/25230741

94. Shaoping N, Mingyong X, Zhihong F, Yiqun W, Aiping Y. Study on the purification and chemical compositions of tea. Carbohydrate Polymers. 2008; 71: 626-633.

95. Karak T, Bhagat RM. Trace elements in tea leaves, made tea and tea infusion: a review. Food Res Int. 2010; 43: 2234-2252.

96. Chow HH, Cai Y, Hakim IA, Crowell JA, Shahi F, et al. Pharmacokinetics and safety of green tea polyphenols after multiple-dose administration of epigallocatechin gallate and polyphenon $E$ in healthy individuals. Clin Cancer Res. 2003; 9: 3312-3319.

PubMed: https://www.ncbi.nlm.nih.gov/pubmed/12960117

97. Lambert JD, Yang CS. Mechanisms of cancer prevention by tea constituents. J Nutr. 2003; 133: 3262S-3267S.

PubMed: https://www.ncbi.nlm.nih.gov/pubmed/14519824 
98. Piskula MK, Terao J. Accumulation of (-)-epicatechin metabolites in rat plasma after oral administration and distribution of conjugation enzymes in rat tissues. J Nutr. 1998; 128: 1172-1178.

PubMed: https://www.ncbi.nlm.nih.gov/pubmed/9649602

99. Lee MJ, Wang ZY, Li H, Chen L, Sun Y, et al. Analysis of plasma and urinary tea polyphenols in human subjects. Cancer Epidemio Biomarkers Prev. 1995; 4: 393-399.

PubMed: https://www.ncbi.nlm.nih.gov/pubmed/7655336

100. Kazuo O, Masayuki S, Natsuki M, Fumio N, Yukihiko H. Methylation of Tea Catechins by Rat Liver Homogenates. Biosci Biotechnol Biochem. 1999; 63: 430-432.

PubMed: https://www.ncbi.nlm.nih.gov/pubmed/10192923

101. Chow HH, Cai Y, Alberts DS, Hakim I, Dorr R, et al. Phase pharmacokinetic study of tea polyphenols following single-dose administration of epigallocatechin gallate and polyphenon E. Cancer Epidemiol Biomarkers Prev. 2001; 10: 53-58.

PubMed: https://www.ncbi.nlm.nih.gov/pubmed/11205489

102. Chuan L, Mao JL, Shuqun S. Structural Identification of Two Metabolites of Catechins and Their Kinetics in Human Urine and Blood after Tea Ingestion. Chem Res Toxicol. 2002; 177-184.

PubMed: https://www.ncbi.nlm.nih.gov/pubmed/10725114

103. Huong TTP, Tsuyoshi Y, Bindu C. Structure-dependent interactions of polyphenols with a biomimetic membrane system. Biochimica Biophysica Acta. 2014; 1838: 2670-2677.

PubMed: https://www.ncbi.nlm.nih.gov/pubmed/25016053
104. Navindra P, Seeram SM, Henning Y, Niu R, Lee $H$, et al. Catechin and Caffeine Content of Green Tea Dietary Supplements and Correlation with Antioxidant Capacity. J Agric Food Chem. 2006; 1599-1603. PubMed: https://www.ncbi.nlm.nih.gov/pubmed/16506807

105. Frei B, Higdon JV. Antioxidant activity of tea polyphenols in vivo: evidence from animal studies. J Nutr. 2003; 3275-3284. PubMed: https://www.ncbi.nlm.nih.gov/pubmed/14519826

106. Lee MJ, Maliakal P, Chen L, Meng X, Bondoc FY, et al. Pharmacokinetics of tea catechins after ingestion of green tea and (-)-epigallocatechin3-gallate by humans: formation of different metabolites and individual variability. Cancer Epidemiol Biomarkers Prev. 2002; 1025-1032. PubMed: https://www.ncbi.nlm.nih.gov/pubmed/12376503

107. Susanne MH, Yantao N, Nicolas HL, Gail DT, Rosario RM, et al Bioavailability and antioxidant activity of tea flavanols after consumption of green tea, black tea, or a green tea extract supplement. Am J Clin Nutr. 2004; 80: 1558-1564.

PubMed: https://www.ncbi.nlm.nih.gov/pubmed/15585768

108. Xiao YX, Cai NZ, Shi YC, Guo YT, Ren YG, et al. Effects and mechanisms of tea for the prevention and management of cancers: An updated review. Crit Rev Food Sci Nutr. 2019; 14: 1-13.

PubMed: https://www.ncbi.nlm.nih.gov/pubmed/30869995

109. Chaoling W. Draft genome sequence of Camellia sinensis var. sinensis provides insights into the evolution of the tea genome and tea quality. Proc Natl Acad Sci USA. 2018; E4151-E4158.

PubMed: https://www.ncbi.nlm.nih.gov/pubmed/29678829 